\title{
Systemic cytokine levels in community-acquired pneumonia and their association with disease severity
}

\author{
G. Antunes*, S.A. Evans", J.L. Lordan*, A.J. Frew*
}

\begin{abstract}
Systemic cytokine levels in community-acquired pneumonia and their association with disease severity. G. Antunes, S. A. Evans, J.L. Lordan, A.J. Frew. C) ERS Journals Ltd 2002.

ABSTRACT: Pro-inflammatory and anti-inflammatory cytokines are important mediators in the host response to infection. In contrast to the pro-inflammatory cytokines little is known about anti-inflammatory cytokines in community-acquired pneumonia (CAP) and their relation to disease severity.

Circulating levels of three pro-inflammatory cytokines (interleukin (IL)-1ß, IL-6 and tumour necrosis factor (TNF)- $\alpha$ ) and two anti-inflammatory cytokines (IL-10, IL-1 receptor antagonist (IL-1ra)) were measured using an enzyme immunoassay on admission, day 3 and day 5 in 24 patients with CAP. The modified British Thoracic Society (BTS) prognostic rule and Acute Physiology and Chronic Health Evaluation (APACHE) II score were used to assess disease severity.

IL-6, TNF- $\alpha$, IL-10 and IL-1ra concentrations were detected in most patients on admission and decreased significantly on day 3 and day 5 in all survivors. A significant difference between the BTS high-risk and low-risk groups was only found for IL-6 (median (range) $477 \mathrm{pg} \cdot \mathrm{mL}^{-1}\left(7.6-1402 \mathrm{pg} \cdot \mathrm{mL}^{-1}\right)$ versus $81.6 \mathrm{pg} \cdot \mathrm{mL}^{-1}\left(0-943 \mathrm{pg} \cdot \mathrm{mL}^{-1}\right)$; $p<0.05)$. IL-6 also correlated with the APACHE II scores on admission.

Concentrations of anti-inflammatory cytokines were elevated on admission in community-acquired pneumonia but they did not correlate with disease severity scores. Eur Respir J 2002; 20: 990-995.
\end{abstract}

\begin{abstract}
*Dept of University Medicine, Southampton General Hospital and ${ }^{\#}$ St. Mary's Hospital, Portsmouth, UK.
\end{abstract}

Correspondence: S. Evans, St. Mary's Hospital, Milton road, Portsmouth, PO3 6AD, UK.

Fax: 442392866735

E-mail: simon.evans@porthosp.nhs.uk

Keywords: Community-acquired pneumonia

cytokines

disease severity score

Received: December 122001

Accepted after revision: May 142002
Community-acquired pneumonia (CAP) is a major cause of death and morbidity despite advances in diagnostic methods, antimicrobial and intensive care treatment [1].

Circulating levels of pro-inflammatory cytokines, such as interleukin (IL)-1 $\beta$, IL-6 and tumour necrosis factor (TNF)- $\alpha$, are usually elevated in CAP [2-4]. However, the relationship of pro-inflammatory cytokines to disease severity is not clear. In addition, little is known about the role of anti-inflammatory cytokines such as IL-10 and IL-1 receptor antagonist (IL-1ra) in CAP in contrast to adult respiratory distress syndrome (ARDS) and septic shock [5, 6]. GLYNN et al. [3] found that plasma IL-10 levels in CAP were higher in patients who met the criteria for systemic inflammatory response syndrome (SIRS) compared to patients who did not. IL-10 levels on admission to hospital also correlated with Acute Physiology and Chronic Health Evaluation (APACHE) II scores. Plasma IL-1ra has been studied in adult and neonatal sepsis and very high levels on admission are associated with less favourable clinical outcome [7, 8].

The present study aimed to investigate the clinical and prognostic relationship of systemic proinflammatory (IL-1 $\beta$, IL-6, TNF- $\alpha$ ) and anti-inflammatory cytokines (IL-10, IL-1ra) to a validated disease specific severity score and a generic severity score in CAP.

Disease severity scores like APACHE II and the simplified acute physiology score were originally designed for use in intensive and high dependency care units to assess multi-organ failure $[9,10]$. These severity scores are not validated for CAP and may be less sensitive at predicting mortality [11]. Several disease-specific scores or prediction rules for CAP have been described such as the British Thoracic Society (BTS) prognostic rule [12-14]. This rule was derived following a large CAP study. The original score consisted of three clinical parameters i.e. respiratory rate $\geqslant 30 \cdot \mathrm{min}^{-1}$, serum urea $>7.0 \mathrm{mmol} \cdot \mathrm{L}^{-1}$ and a diastolic blood pressure $\leqslant 7.98 \mathrm{kPa}(\leqslant 60 \mathrm{mmHg})$. A positive rule was associated with a 21 -fold increase in mortality [15]. The rule has recently been modified by NeILl et al. [16] to include mental confusion and subsequently validated in a large study [17].

\section{Materials and methods}

The study was conducted at a district general hospital in the UK, between August 1997-February 1998. Twenty-eight consecutive patients admitted through the Medical Admission Unit and the Accident and Emergency department with a diagnosis of CAP were enrolled in the study. The local ethics and research committee approved the study and informed consent was obtained from all patients.

Pneumonia was defined as a febrile illness with 
radiological evidence of consolidation on chest radiograph not known to be present prior to hospital admission. Exclusion criteria were: age $<18$ yrs, pneumonia distal to endobronchial obstruction, pulmonary tuberculosis, bronchiectasis, underlying systemic autoimmune disease and immunocompromised states including maintenance oral corticosteroids.

Demographic, clinical and laboratory data were collected on admission, day 3 and day 5. Selection of antibiotic therapy was based on published BTS guidelines [15]. Severity of illness was assessed by both the modified BTS prognostic rule (high risk defined as $\geqslant$ two adverse prognostic parameters) and the APACHE II score $[9,16]$. Chest radiographs were performed on admission and assessed independently by a consultant radiologist.

Blood samples were collected on admission, day 3 and 5. Samples were then centrifuged at $510 \times g$ for $10 \mathrm{~min}$, stored at $-20^{\circ} \mathrm{C}$ and then analysed in a single batch. Circulating levels of IL- $1 \beta$, TNF- $\alpha$, IL-6, IL-10 and IL-1ra were measured using commercially available quantitative sandwich enzyme immunoassays (Cytoscreen and EASIA; Biosource Europe SA, Nivelles, Belgium). The manufacturer's reported serum sensitivity thresholds and normal range values were used: IL-1 $\beta \quad 1 \mathrm{pg} \cdot \mathrm{mL}^{-1}\left(2-4 \mathrm{pg} \cdot \mathrm{mL}^{-1}\right)$; TNF- $\alpha 2 \mathrm{pg} \cdot \mathrm{mL}^{-1} \quad\left(3-15 \mathrm{pg} \cdot \mathrm{mL}^{-1}\right) ;$ IL-6 $1 \mathrm{pg} \cdot \mathrm{mL}^{-1}$ $\left(2-30 \mathrm{pg} \cdot \mathrm{mL}^{-1}\right) ; \mathrm{IL}-105 \mathrm{pg} \cdot \mathrm{mL}^{-1}\left(1-10 \mathrm{pg} \cdot \mathrm{mL}^{-1}\right)$ and IL-1ra $4 \mathrm{pg} \cdot \mathrm{mL}^{-1}\left(4-30 \mathrm{pg} \cdot \mathrm{mL}^{-1}\right)$.

Most of the data were not normally distributed and therefore nonparametric tests (Mann-Whitney U-test, Wilcoxon signed rank test for pairs) were used to compare cytokine levels and BTS high- and low-risk groups. Normally distributed data (age, serum urea, respiratory rate) were analysed by unpaired t-tests. The correlation between APACHE II scores and cytokine levels on admission was calculated by using Spearman's Rank correlation coefficient. Statistical significance was taken as a p-value $<0.05$.

\section{Results}

Twenty-eight patients were studied, four of whom were excluded from the study: two with bronchiectasis, a single patient with active systemic lupus erythrematosis and one other with chronic obstructive pulmonary disease (COPD) on maintenance oral corticosteroids. The remaining 24 patients had a mean age of $58 \mathrm{yrs}$ (range, 21-89 yrs) and 12 were male. Ten patients $(46 \%)$ were aged $>70$ yrs. Nine patients $(38 \%)$ were found to have significant comorbidity (ischaemic heart disease, cerebrovascular disease, chronic renal failure and severe COPD) and eight patients reported taking antibiotics prior to hospital admission. Routine microbiological investigations included blood cultures on admission in all patients, sputum for bacterial culture in patients with a productive cough $(\mathrm{n}=20)$ and paired serology for Mycoplasma pneumoniae, Legionella pneumophila, Chlamydia psittaci and Coxiella burnetii $(\mathrm{n}=17)$. A causative pathogen was only found in three patients $(13 \%)$.

Eleven patients had $\geqslant$ two adverse prognostic factors and therefore included in the BTS high-risk
Table 1. - Clinical and laboratory parameters on admission in the British Thoracic Society high-risk and low-risk groups

\begin{tabular}{lccc}
\hline Parameters & $\begin{array}{c}\text { High-risk } \\
\text { group }\end{array}$ & $\begin{array}{c}\text { Low-risk } \\
\text { group }\end{array}$ & Significance \\
\hline $\begin{array}{l}\text { Subjects n } \\
\text { Age yrs }\end{array}$ & 11 & 13 & \\
Temperature ${ }^{\circ} \mathrm{C}$ & $38.2 \pm 0.8$ & $38.4 \pm 0.5$ & 0.05 \\
${\mathrm{~Pa}, \mathrm{O}_{2} \mathrm{kPa} ;}^{\mathrm{Fi}, \mathrm{O}_{2} 0.21}$ & $8.12 \pm 1.2$ & $9.32 \pm 1.4$ & $<0.05$ \\
$\mathrm{CRP} \mathrm{mg} \cdot \mathrm{L}^{-1}$ & $106.6 \pm 143.1$ & $49.8 \pm 42.2$ & 0.19 \\
$\begin{array}{l}\mathrm{APACHE} \text { II } \\
\quad \text { score }\end{array}$ & $12.0 \pm 3.2$ & $6.2 \pm 3.4$ & $<0.005$ \\
$\begin{array}{l}\text { Length of hospital } \\
\quad \text { stay days }\end{array}$ & $9.0 \pm 5.3$ & $5.9 \pm 2.1$ & 0.06 \\
\hline
\end{tabular}

Data are presented as mean \pm SD unless otherwise indicated. $\mathrm{Pa}_{\mathrm{a}} \mathrm{O}_{2}$ : oxygen tension in arterial blood; $\mathrm{Fi}_{\mathrm{i}} \mathrm{O}_{2}$ : inspiratory oxygen fraction; CRP: C-reactive protein; APACHE: Acute Physiology and Chronic Health Evaluation.

group. The mean age of the BTS high-risk group was 67.5 yrs compared with 50 yrs in the low-risk group. $\mathrm{C}$-reactive protein (CRP) was measured on admission in 19 patients. CRP levels correlated well with serum IL-6 concentrations on admission $(\mathrm{p}<0.01)$ but there was no significant difference in CRP levels between the BTS high- and low-risk groups. APACHE II scores were significantly higher $(\mathrm{p}<0.005)$ and oxygen tension in arterial blood $\left(\mathrm{Pa}_{\mathrm{a}} \mathrm{O}_{2}\right)$ was significantly lower $(\mathrm{p}<0.05)$ in the BTS high-risk group (table 1$)$. There were three deaths all attributed to CAP and all from the BTS high-risk group.

\section{Cytokine levels on admission}

Circulating plasma TNF- $\alpha$, IL-6 and IL-1ra levels were detected and elevated in the majority of patients on admission but most patients did not have elevated levels of IL-1 $\beta$ and IL-10 (table 2).

\section{Changes in cytokine levels over time}

A significant reduction in individual plasma cytokine levels was observed on days 3 and 5 compared with admission for TNF $\alpha$, IL-6, IL-1ra and IL-10 (fig. 1a and 1b). The plasma levels of TNF- $\alpha$, IL-6 and IL-1ra remained elevated or were higher than on admission in two of the patients that died of CAP. A third patient died within $24 \mathrm{~h}$ of admission to hospital from septic shock and therefore no further samples were available for analysis.

Relationship of cytokine levels to disease severity scores

Modified British Thoracic Society score. The only statistically significant difference found between the BTS high-risk and low-risk groups was for IL-6 on admission $(\mathrm{p}<0.05)$ (table 3$)$. 
Table 2. - Cytokine levels on admission

\begin{tabular}{lccccc}
\hline & IL-1 $\beta$ & TNF- $\alpha$ & IL-6 & IL-1ra & IL-10 \\
\hline $\begin{array}{l}\text { Patients with } \\
\text { detectable levels }\end{array}$ & 3 & 24 & 21 & 24 & 16 \\
$\begin{array}{l}\text { Patients with } \\
\quad \text { elevated levels }\end{array}$ & 2 & 17 & 19 & 24 & 5 \\
$\begin{array}{l}\text { Median } \mathrm{pg} \cdot \mathrm{mL}^{-1} \\
\text { Range } \mathrm{pg} \cdot \mathrm{mL}^{-1}\end{array}$ & 0.0 & 18.3 & 160.7 & 1939 & 2.4 \\
\hline
\end{tabular}

IL: interleukin; TNF- $\alpha$ : tumour necrosis factor- $\alpha$; IL-1ra: IL-1 receptor antagonist. $\mathrm{n}=24$ for patients with both detectable and elevated levels.

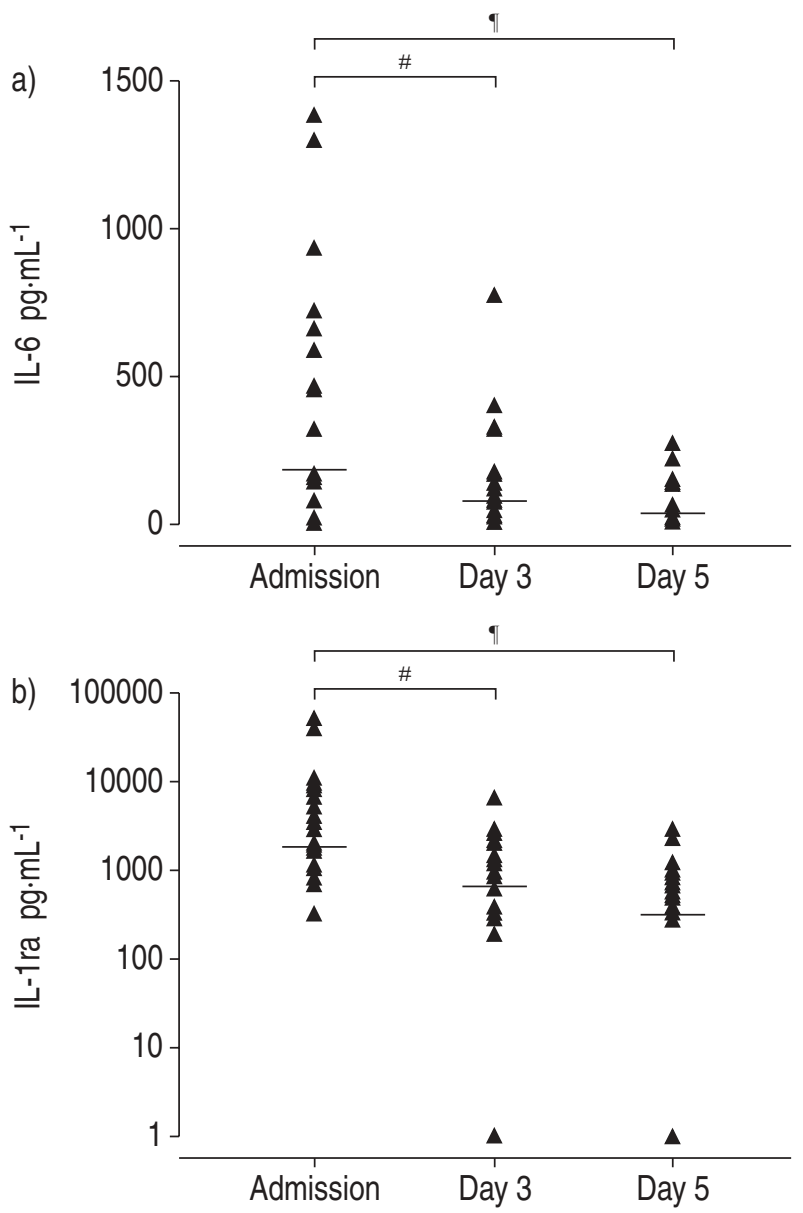

Fig. 1.-a) Interleukin (IL)-6 levels on admission, day 3 and day 5. Solid lines: median bars. ${ }^{\#}: \mathrm{p}=0.02 ;{ }^{\circ}: \mathrm{p}=0.06$. b) IL-1 receptor antagonist (IL-1ra) levels on admission, day 3 and day 5. Solid lines: median bars. ${ }^{\#}: \mathrm{p}=0.03 ;{ }^{\circ}: \mathrm{p}=0.001$.

Acute Physiology and Chronic Health Evaluation II score. The mean APACHE II score was 8.9 (range 1-16). A positive correlation was found between IL-6 levels and APACHE II scores on admission ( $\mathrm{r}=0.441$; $\mathrm{p}<0.05$ ) (fig. 2).

Serum urea was the only individual prognostic factor to correlate with cytokine levels (TNF- $\alpha$, IL-6 and IL-1ra) on admission, day 3 and day $5(\mathrm{p}<0.05)$. There was no history of pre-existing renal impairment in any of the patients studied and renal function returned to normal in all the survivors. No difference was found in cytokine levels between smokers and nonsmokers, and those aged $>70$ yrs $(n=10)$ and $<70$ yrs. IL-1 ra levels on admission were significantly lower in those patients commenced on antibiotics prior to hospitalisation (median level: 1,063 versus $\left.4,383 \mathrm{pg} \cdot \mathrm{mL}^{-1} ; \mathrm{p}<0.01\right)$. TNF- $\alpha$ and IL-6 levels on admission also tended to be lower in this subgroup. The presence of comorbidity was associated with higher IL-6 levels on admission (median level: 327 versus $\left.155 \mathrm{pg} \cdot \mathrm{mL}^{-1} ; \mathrm{p}<0.01\right)$. Pro-inflammatory and anti-inflammatory cytokine
ratios

The ratios between the concentrations of IL-1ra and IL-1 $\beta$, TNF- $\alpha$ and IL-10, IL-6 and IL-10 of both BTS high- and low-risk groups on admission were calculated but none reached statistical significance.

\section{Discussion}

This study has demonstrated elevated circulating levels of TNF- $\alpha$, IL- 6 and IL-1ra on admission in most patients with CAP and a temporal pattern of systemic cytokine expression. The serum levels of these cytokines declined rapidly over 5 days in all the survivors. Serum IL-6 correlated best with both disease-specific and generic severity scores and may therefore be a valid marker of inflammation in CAP.

The present authors were primarily interested in the relationship of cytokines to clinical severity scores. In CAP, IL-1 $\beta$ and TNF- $\alpha$ are produced at the site of infection and then to a variable extent spill over into the circulation [18, 19]. However many of the best prognostic markers in CAP relate to the systemic effects of sepsis rather than pulmonary effects. For example, in the modified BTS severity score three of the four parameters are nonpulmonary (diastolic blood pressure, serum urea and mental confusion) $[16,17]$. It therefore appears that the systemic effects of sepsis are of fundamental importance in determining the prognosis of CAP, providing a rationale for studying the systemic inflammatory response in this condition.

Ideally both the local and systemic cytokine responses should have been studied. There are, however, problems in performing bronchoalveolar lavage (BAL) in this population especially if patients with a range of disease severity are to be studied. BAL would be 
Table 3.-Cytokine levels on admission, day 3 and day 5 in the British Thoracic Society (BTS) high-risk and low-risk groups

\begin{tabular}{|c|c|c|c|c|}
\hline Cytokine* & Time of sample & BTS high-risk $\mathrm{pg} \cdot \mathrm{mL}^{-1}$ & BTS low-risk $\mathrm{pg} \cdot \mathrm{mL}^{-1}$ & $\mathrm{p}$-value \\
\hline \multirow[t]{3}{*}{ TNF- $\alpha$} & Admission & $19.4(12-211)$ & $16.0(4.6-25)$ & NS \\
\hline & Day 3 & $17.2(0-34.6)$ & $12.6(0-22.6)$ & NS \\
\hline & Day 5 & $15.4(0-23.6)$ & $10.8(0-20.2)$ & NS \\
\hline \multirow[t]{3}{*}{ IL-6 } & Admission & $477.0(7.6-1402)$ & $81.6(0-943)$ & $<0.05$ \\
\hline & Day 3 & $116.4(0-784)$ & $13.8(0-399)$ & NS \\
\hline & Day 5 & $58.7(0-274.4)$ & $1.0(0-139)$ & NS \\
\hline \multirow[t]{3}{*}{ IL-1 ra } & Admission & $5266.0(318-50975)$ & $1731.0(711-10548)$ & NS \\
\hline & Day 3 & $988.0(0-6389)$ & $899.0(0-2799)$ & NS \\
\hline & Day 5 & $724.0(0-2877)$ & $318.0(0-5678)$ & NS \\
\hline \multirow[t]{3}{*}{ IL-10 } & Admission & $3.3(0-68.5)$ & $1.0(0-46.2)$ & NS \\
\hline & Day 3 & $0.0(0-12.4)$ & $0.0(0-13)$ & NS \\
\hline & Day 5 & $0.0(0-6.8)$ & $0.0(0-2.0)$ & NS \\
\hline
\end{tabular}

Data are presented as median (range). TNF- $\alpha$ : tumour necrosis factor- $\alpha$; IL: interleukin; IL-1ra: IL-1 receptor antagonist; NS: not significant. *: IL-1 $\beta$ values not shown due to small number of patients with detectable levels.

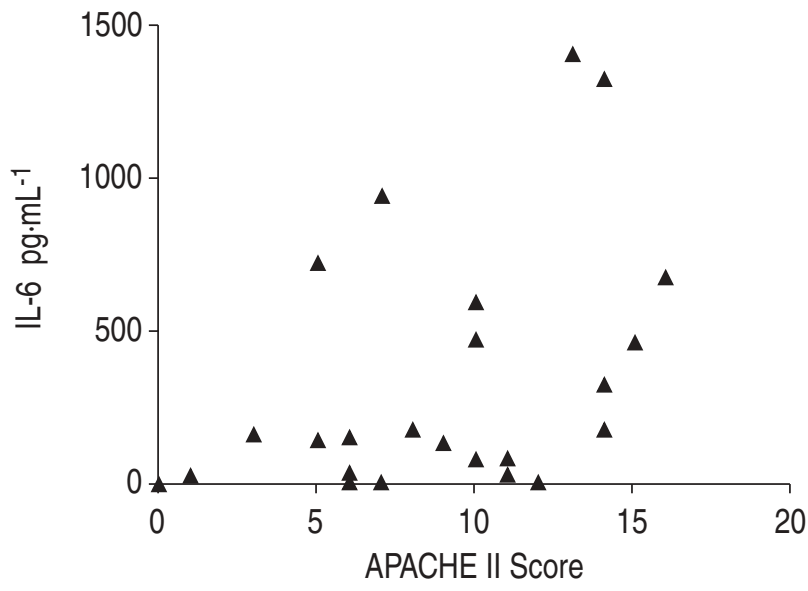

Fig. 2.-Correlation between admission Acute Physiology and Chronic Health Evaluation (APACHE) II scores and Interleukin (IL) 6 levels. $r=0.44 ; \mathrm{p}<0.05$.

feasible in those patients intubated on the intensive care unit, and those who were clinically well. It would not however have been ethically acceptable to perform BAL on those patients who were ill but not already intubated, where the likelihood of clinically useful information would be low and the risk of complications considerable. In addition performing BAL in this small subgroup would have been unlikely to yield statistically useful results.

Other limitations of the present study relate to the number of uncontrolled factors present before patients entered the study. Patients are admitted at different stages of their disease meaning that there is no real day zero. Prior prescription of antibiotics in as many as one-third of patients may have resulted in the modulation of the inflammatory response and cytokine expression. The relatively small number of patients, particularly with severe CAP, in the present study may also have resulted in an inability to demonstrate real biological relationships found in other studies [7, 20].

In sepsis and CAP the measurement of systemic cytokine concentrations may be useful in determining the magnitude of the pro-inflammatory response and prognosis. Many studies have analysed cytokine concentrations at single time points $[2,7,20]$, but temporal changes in cytokines may have greater clinical value and perhaps add to the utility of clinical severity scores. The temporal trend of cytokine levels may have potential for determining the optimal time when specific anticytokine or immunomodulatory therapy would be appropriate i.e. persistently elevated TNF- $\alpha$ or IL- 6 levels.

This study suggests that pro-inflammatory cytokines are associated with a poor prognosis in CAP. Those patients with a high-risk BTS score had higher IL-6 levels on admission than those with a low risk score (table 3). A similar picture was seen with the generic APACHE II score. Persistent elevation may be particularly significant in that two of the three patients who died had persistently elevated levels of TNF- $\alpha$ and IL-6. The third nonsurvivor succumbed to septic shock within $24 \mathrm{~h}$ of admission to hospital. In contrast, a significant reduction in serum IL-6 concentrations was observed on day 3 and 5 in all the survivors. These findings are consistent with previous studies in septic shock and SIRS where persistent elevation of TNF- $\alpha$ and IL- 6 has been a marker of poor prognosis $[20,21]$. The findings of Moussa et al. [4] are, however, at variance with this, finding elevated IL-6 levels on admission in only eight out of their 34 patients with CAP, despite the study population being similar to that of the present study in terms of preadmission antibiotic treatment and the proportion with a high BTS score. The apparent difference may reflect the use of IL- 6 and TNF- $\alpha$ assays with lower sensitivity.

It has been proposed that CRP is a sensitive marker of pneumonia severity [22]. In contrast to this study the present authors observed that CRP levels correlated well with serum IL-6 concentrations on admission but were less helpful for assessing the severity of CAP and predicting poor outcome, as all three nonsurvivors had comparatively low CRP levels on admission.

The pro-inflammatory response is regulated by the anti-inflammatory components of the immune system 
$[5,23]$. An imbalance between these two aspects of the inflammatory response may be deleterious. Elevated plasma IL-10 levels and raised IL-10 to TNF- $\alpha$ ratios have been associated with poor outcome and increased mortality in sepsis [24, 25]. Conversely, TANIGUCHI et al. [21] found that an increase in the ratio of IL-6 to IL-10 correlated with a poor outcome in patients with SIRS, while low concentrations of IL-10 and IL-1ra in BAL of patients with ARDS appears to be associated with a poor prognosis [6]. It therefore seems that both over-robust and inadequate anti-inflammatory responses can be associated with a poor prognosis, although insufficient data are available to define an appropriate response in any individual context.

In the present study most patients (67\%) had detectable IL-10 levels in the serum but only $21 \%$ showed elevated levels. This appears to show that most patients with CAP do not mount a significant systemic IL-10 response. It has been suggested that IL-10 is a marker of more severe disease. Whilst a previous study has shown a relationship between plasma IL-10 and disease severity in CAP [3], there was a considerable overlap in IL-10 levels between the BTS low- and high-risk groups in the present study $(p=0.18)$, with markedly elevated levels seen in the two of the three patients who died. It may therefore be that IL-10 is a marker of severe disease but this study did not confirm that relationship.

In contrast all patients had raised serum IL-1ra concentrations on admission and a rapid, significant reduction in these concentrations was observed on day 3 and day 5. To the best of the authors' knowledge systemic IL-1ra levels have not been studied in CAP. IL-1ra is produced in concentrations 10-100-fold greater than IL-1 $\beta$ after lipopolysaccharide stimulation and may partly explain the comparatively high concentrations of this cytokine in the serum compared to the other cytokines studied [26]. No significant difference in IL-1ra levels was demonstrated between the BTS high- and low-risk groups (on admission or later) and no correlation between IL-1ra and IL-1 $\beta$ was found. It therefore seems that a systemically detectable IL-1ra response is ubiquitous in CAP but not a useful severity marker. In contrast, few of the patients studied had raised serum IL-1 $\beta$ levels on admission. This may therefore reflect either lung production, or merely the extent of 'spillover' despite significant lung production.

Many large multicentre trials employing immunomodulatory therapies for sepsis have failed to demonstrate an improvement in outcome [27, 28]. Numerous explanations have been proposed among which patient selection and the timing of immunomodulatory therapy appears to be important.

Given this disappointing situation is there a potential for immunomodulatory therapy in CAP? Clinical severity scores in CAP could identify a subgroup of high-risk patients. Further selection could then be made on the basis of high pro-inflammatory cytokine levels, especially in those patients where they do not fall rapidly in response to treatment. This study has shown that IL-6 appears to reflect clinical status in CAP better than TNF- $\alpha$ or IL-1, and may therefore have particular potential for improving patient selection for such studies.

The present study would suggest that antiinterleukin-6 therapy might be an appropriate choice of treatment. The present authors are not aware of any data on anti-interleukin-6 antibodies in human sepsis, but such treatment has been shown to be safe in another context [29]. The effects of anti-interleukin-6 therapy are difficult to predict however, because of the potential pro- or anti-inflammatory effects of interleukin-6, such effects probably being dependent on the pattern of cytokine activation in the individual patient [30].

Acknowledgements. The authors would like to thank A. Beale for interpretation of all chest radiographs and $\mathrm{A}$. French for assistance with recruitment of patients.

\section{References}

1. Hook EW, Horton CA, Schaberg DR. Failure of intensive care unit support to influence mortality from pneumococcal bacteremia. JAMA 1983; 249: 10551057.

2. Puren AJ, Feldman C, Savage N, Becker PJ, Smith C. Patterns of cytokine expression in communityacquired pneumonia. Chest 1995; 107: 1342-1349.

3. Glynn P, Coakley R, Kilgallen I, Murphy N, O'Neill S. Circulating interleukin 6 and interleukin 10 in community acquired pneumonia. Thorax 1999; 54: $51-55$.

4. Moussa K, Michie HJ, Cree IA, et al. Phagocyte function and cytokine production in community acquired pneumonia. Thorax 1994; 49: 107-111.

5. Gomez-Jimenez J, Martin MC, Sauri R, et al. Interleukin-10 and the monocyte/macrophage-induced inflammatory response in septic shock. $J$ Infect Dis 1995; 171: 472-475.

6. Donnelly SC, Strieter RM, Reid PT, et al. The association between mortality rates and decreased concentrations of interleukin-10 and interleukin-1 receptor antagonist in the lung fluids of patients with the adult respiratory distress syndrome. Ann Intern Med 1996; 125: 191-196.

7. Gardlund B, Sjolin J, Nilsson A, Roll M, Wickerts C-J, Wretlind B. Plasma levels of cytokines in primary septic shock in humans: correlation with disease severity. J Infect Dis 1995; 172: 296-301.

8. De Bont ESJM, De Leij LHFM, Okken A, Baarsma $\mathrm{R}$, Kimpen JLL. Increased plasma concentrations of interleukin-1 receptor antagonist in neonatal sepsis. Pediatr Res 1995; 37: 626-629.

9. Knaus WA, Draper EA, Wagner DP, Zimmerman JE. APACHE II: a severity of disease classification system. Crit Care Med 1985; 13: 818-828.

10. Le Gall J-R, Lemeshow S, Saulnier F. A new Simplified Acute Physiology Score (SAPS II) based on a European/North American multicenter study. JAMA 1993; 270: 2957-2963.

11. Fine MJ, Hanusa BH, Lave JR, et al. Comparison of a disease-specific and a generic severity of illness measure for patients with community acquired pneumonia. J Gen Intern Med 1995; 10: 359-368. 
12. Ewig S, Bauer T, Hasper E, Pizzulli L, Kubini R, Luderitz B. Prognostic analysis and predictive rule for outcome of hospital-treated community-acquired pneumonia. Eur Respir J 1995; 8: 392-397.

13. Fine MJ, Auble TE, Yealy DM, et al. A prediction rule to identify low-risk patients with communityacquired pneumonia. $N$ Engl J Med 1997; 336: 243250 .

14. Research committee of the British Thoracic Society and the Public Health Laboratory Service. Community acquired pneumonia in adults in British hospitals in 1982-83: a survey of aetiology, mortality, prognostic and outcome. $Q J$ Med 1987; 62: 195-220.

15. British Thoracic Society. Guidelines for the management of community acquired pneumonia in adults admitted to hospital. Br J Hosp Med 1993; 49: 346350.

16. Neill AM, Martin IR, Weir R, et al. Community acquired pneumonia: aetiology and usefulness of severity criteria on admission. Thorax 1996; 51: 1010-1016.

17. Lim WS, Lewis S, Macfarlane JT. Severity prediction rules in community acquired pneumonia: a validation study. Thorax 2000; 55: 219-223.

18. Dehoux MS, Boutten A, Ostinelli J, et al. Compartmentalized cytokine production within the human lung in unilateral pneumonia. Am J Respir Crit Care Med 1994; 150: 710-716.

19. Monton C, Torres A, El-Ebiary M, Filella X, Xaubet A, De la Bellacasa JP. Cytokine expression in severe pneumonia: a bronchoalveolar lavage study. Crit Care Med 1999; 27: 1745-1753.

20. Pinsky MR, Vincent J-L, Deviere J, Alegre M, Kahn RJ, Dupont E. Serum cytokine levels in human septic shock. Relation to multiple-system organ failure and mortality. Chest 1993; 103: 565-575.

21. Taniguchi T, Koido Y, Aiboshi J, Yamashita T, Suzaki S, Kurokawa A. Change in the ratio of interleukin-6 to interleukin-10 predicts a poor outcome in patients with systemic inflammatory response syndrome. Crit Care Med 1999; 27: 1262-1264.
22. Smith RP, Lipworth BJ, Cree IA, Spiers EM, Winter JH. C-Reactive Protein. A clinical marker in community-acquired pneumonia. Chest 1995; 108: $1288-1291$.

23. Cassatella MA, Meda L, Bonora S, Ceska M, Constantin G. Interleukin 10 (IL-10) inhibits the release of proinflammatory cytokines from human polymorphonuclear leukocytes. Evidence for an autocrine role of tumor necrosis factor and IL-1 $\beta$ in mediating the production of IL-8 triggered by lipopolysaccharide. J Exp Med 1993; 178: 2207-2211.

24. Lehmann AK, Halstensen A, Sornes S, Rokke O, Waage A. High levels of interleukin 10 in serum are associated with fatality in meningococcal disease. Infect Immun 1995; 63: 2109-2112.

25. Van Dissel JT, Van Langevelde P, Westendorp RGJ, Kwappenberg K, Frolich M. Anti-inflammatory cytokine profile and mortality in febrile patients. Lancet 1998; 351: 950-953.

26. Dinarello CA. Interleukin-1, interleukin-1 receptors and interleukin-1 receptor antagonist. Int Rev Immunol 1998; 16: 457-499.

27. Cohen J, Carlet J. INTERSEPT: an international, multicenter, placebo-controlled trial of monoclonal antibody to human tumor necrosis factor- $\alpha$ in patients with sepsis. Crit Care Med 1996; 24: 1431-1440.

28. Opal SM, Fisher CJ, Pribble JP, et al. The Interleukin1 Receptor Antagonist Sepsis Investigator Group. The confirmatory interleukin-1 receptor antagonist trial in severe sepsis: a phase III randomized, double-blind, placebo-controlled, multicenter trial. Crit Care Med 1997; 25: 1115-1124.

29. Lu ZY, Brailly H, Wijdenes J, Rossi JF, Klein B. Measurement of whole body interleukin-6 (IL-6) production: prediction of the efficacy of anti-IL-6 treatments. Blood 1995; 86: 3123-3131.

30. Tilg H, Trehu E, Atkins MB, Dinarello CA, Meir JW. Interleukin-6 (IL-6) as an anti-inflammatory cytokine: induction of circulating IL-1 receptor antagonist and soluble tumour necrosis factor receptor p55. Blood 1994; 83: 113-118. 